\title{
Analysis of DNA methylation level and mRNA expression of 'Transient Receptor Ankyrin Member 1 (TRPA1) in endometriosis-associated pain
}

\author{
Ocktariyana $^{\mathrm{a}, \mathrm{i}}$, Nurul Hikmawati ${ }^{\mathrm{b}}$, Andon Hestiantoro ${ }^{\mathrm{c}, \mathrm{d}}$, Raden Muharam ${ }^{\mathrm{c}, \mathrm{d}}$, Muhammad Luky Marwali, \\ Agus Surur, Tiara Aninditha ${ }^{\mathrm{f}}$, Gita Pratama, ${ }^{\mathrm{c}, \mathrm{d}}$, Anisah Zahrah ${ }^{\mathrm{b}}$, Nabilla Farah Naura ${ }^{\mathrm{g}}$, Asmarinah ${ }^{\mathrm{c}, \mathrm{h}^{*}}$ \\ ${ }^{a}$ Doctoral Program in Biomedical Sciences, Faculty of Medicine, Universitas Indonesia, Jakarta, Indonesia \\ ${ }^{b}$ Master Program in Biomedical Sciences, Faculty of Medicine, Universitas Indonesia, Jakarta, Indonesia \\ 'Human Reproductive, Infertility, and Family Planning Cluster, Indonesian Medical Education and Research Institute (IMERI), Faculty of \\ Medicine, Universitas Indonesia, Jakarta, Indonesia \\ ${ }^{d}$ Department of Obstetrics and Gynecology, Faculty of Medicine, Universitas Indonesia, Cipto Mangunkusumo Hospital, Jakarta, Indonesia \\ ${ }^{e}$ Endometriosis Center, Fatmawati Hospital, Jakarta, Indonesia

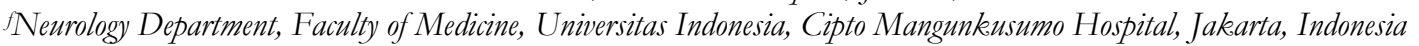 \\ ${ }^{g}$ Undergraduate Program in Biological Sciences, Faculty of Mathematics and Natural Sciences, Universitas Indonesia, Jakarta, Indonesia \\ ${ }^{b}$ Medical Biology Department, Faculty of Medicine, Universitas Indonesia, Jakarta, Indonesia \\ iDepartment of Midwifery, Politeknik Kesehatan Palembang, Ministry of Health, Palembang, Indonesia
}

Received 28th October 2020 / Accepted 12th May 2021

\begin{abstract}
Transient Receptor Ankyrin Member 1 (TRPA1) is an ion channel family protein that regulates pain sensation through sensory neurons' activity. This study's purpose to analyzes the DNA methylation and mRNA expression level of the TRPA1 gene in endometriosis and its correlation with pain level. Twenty samples of peritoneal endometriosis and endometrial samples were obtained from women with endometriosis, which was subsequently compared to 20 endometrial samples of women without endometriosis. The DNA methylation level of TRPA1 was analyzed using Methylation-specific PCR (MSPCR) and ImageJ software, while the mRNA expression of TRPA1 was analyzed using qRT-PCR. Furthermore, the pain level was measured using the numeric rating scale (NRS) by interviewing all the women. This study showed that there was a significant difference in the mRNA expression of TRPA1 in peritoneal endometriosis. The TRPA1 was unmethylated in both peritoneal and endometrial samples in endometriosis. However, DNA Methylation level of TRPA1 in peritoneal and endometrial of endometriosis compared to normal endometrial were no significant difference. Additionally, there was no correlation between DNA methylation level and mRNA expression level of TRPA1 in all samples, along with the endometriosis-associated pain.
\end{abstract}

Keywords: DNA methylation, endometriosis, mRNA expression, pain, TRPA1

\section{INTRODUCTION}

Endometriosis is a chronic disease characterized by the growth of the functional layer of endometrial-like tissue outside the uterus and very sensitivity to hormones (Taylor \& Lebovic 2014).
Dysmenorrhea, dyspareunia, abnormal bleeding, chronic pelvic pain, pain during ovulation, fatigue, and infertility are common symptoms in endometriosis women (Young et al., 2015;

\footnotetext{
*Author for correspondence: Asmarinah. Medical Biology Department, Faculty of Medicine, Universitas Indonesia, Jl. Salemba Raya No.6, Jakarta Pusat 10430, Indonesia. Email - asmarinah.si@gmail.com
} 
Marinho et al., 2018; Eisenberg et al., 2018). A study reported that women with chronic pelvic pain possess a 6.6-fold risk of endometriosis than women without chronic pelvic pain, but the correlation between the severity of endometriosis and chronic pelvic pain has remained uncertain (Howard, 1999).

The epigenetic mechanisms in several genes might play important roles in endometriosis pathogenesis (Xue et al., 2007; Wu et al., 2015; Nasu et al., 2011). Epigenetics is a study of chromosome alteration, which modifies no basic DNA sequence yet changes its gene expression. DNA methylation, histone modification, and miRNA non-coding are examples of epigenetic mechanisms (Das \& Singal, 2017).

Epigenetics mechanism tends to change the pain sensations in a person due to environmental factors. A study reported that the methylated DNA sequences in 5.2 million loci of pain-related genes taken from 25 twins couples showed increased TRPA1's DMRs (Buchheit et al., 2012; Bell et al., 2014). furthermore, A study identified the number of genes overexpressed by the nerve fibers in nociceptors, including the TRP and TRPV1 ion channel family proteins, SCN9A, SCN11A, and the P2X purinergic receptor family proteins that play a role in pain mechanism (Julius \& Basbaum, 2001). However, the correlation between the mRNA expression level and DNA Methylation level of the TRPA1 gene in endometriosis-associated pain is not reported yet.

TRPA1 is a member of the TRP superfamily of a non-selective ion channel. It is differentiated into seven families: TRPC, TRPN, TRPM, TRPML, TRPP, TRPA, and TRPV. (Pedersen et al., 2005; Clapham, 2007). Transient Receptor Ankyrin Member 1 (TRPA1) induces the pain sensation through a sensory neuron's activity (Andersson et al., 2008; E. Fernandes et al., 2011; E. S. Fernandes et al., 2012). Greaves et al. (2014) reported that the mRNA expression level of TRPA1 increased in peritoneal endometriosis, but it has not unknown yet in endometrial endometriosis compared to endometrial without endometriosis patients and epigenetic perspective. We assumed that there are differences and correlations between epigenetic and genetic regulation of TRPA1 in endometriosis-associated pain.

\section{MATERIALS AND METHODS}

\section{Sample preparation}

Samples were obtained from both Fatmawati Hospital and Cipto Mangunkusumo Hospital. We collected 40 participants. We have determined the number of samples with a formula:

$$
N=\frac{(\mathrm{Z} \alpha)^{2} p(1-p)}{d^{2}}
$$

The proportion of endometriosis $(p)$ in Indonesia is $30 \%$, and the precision value $\left(d^{2}\right)$ is $20 \%$. (Hendarto et al., 2010). $Z \alpha$ value is the error rate in the specified statistic, which is 1.96.

Participants' inclusion criteria were women aged $\leq 45$ years; have a classic menstrual cycle of about 25-30 days, approved informed consent to taken many samples, willing to fill out the questionnaire and interview, at least graduated from senior high school. Participants without endometriosis were no suspicion of endometriosis, adenomyosis, endometrial hyperplasia, malignancy, and Hydatidiform mole. Also, a pregnant program IVF comes to the hospital undergo micro-curettage. Endometriosis participants were diagnosed with endometriosis and confirmed by laparoscopy and histopathological examination. The severity of endometriosis III-IV degree was based on the American Society Reproductive scale and approved to taken endometrial tissue with microcurettage. Furthermore, this study has excluded any suspicion or history of cancer, experienced a toothache, severe headache, trauma after surgery in all participants while undergoing the research.

The participants were divided into two groups, 20 endometriosis women as a case group and 20 without endometriosis women as a control group.

The case group was obtained two types of samples that were 20 peritoneal endometriosis taken by biopsy and 20 endometrial tissue taken by micro-curettage technique.

Furthermore, all participants were interviewed and filled in the questions related to characteristics, disease history. We have measured the pain intensity used the uni-dimensional pain assessment questionnaires (Hawker et al., 2011; Francesca et al., 2007); that was NRS also 
confirmed with both FPS and several questions that aimed to reduce the subjectivity of the answers. Before filled the questionnaire, the subject explained information about endometriosis-related pain. The determination of pain intensity was determined based on the most severe pain sensations the study subjects had felt over the past three months when the study was conducted.

This study was approved by The Ethics Committee Faculty of Medicine, Universitas Indonesia (No: 0126/UN2.F1/ETIK/2018 and ND-951/UN2.F1/ETIK/PPM.00.02/2019).

\section{DNA extraction}

The DNA was extracted from 20-25 $\mathrm{mg}$ of samples using the $g S Y N C^{\mathrm{TM}} D N A$ Extraction Kit (Geneaid, Taiwan).

\section{Bisulfite treatment}

The isolated DNA was converted by bisulfite conversion technique using the Epitect Bisulfite Kit (Qiagen 59104, Germany).

\section{Analysis of DNA methylation level of TRPA1}

The promoter region of TRPA1 was targeted for analysis. The methylation level of the TRPA1's CpG site was analyzed using methylation-specific PCR (MS-PCR). We used the specific designed primers from MethPrimer as follow: the methylated-specific primer (F)5'- GCGTTGTTG TAGTTGTAGGATAGC-3' and (R) 5' 'TTCTAA AAAAAATTCTCAAACCCG-3', and the unmethylated-specific primer (F) 5'-TGTGTTGT 'TGTAGTTGTAGGATAGTG-3' and (R)5'-T'T CTAAAAAAAAT'TCTCAAACCCAC-3'. The methylated-specific primer had $183 \mathrm{bp}$ in the length of amplification product with the annealing temperature of $54^{\circ} \mathrm{C}$, while the unmethylatedspecific primer had $184 \mathrm{bp}$ in the length of amplification product with the annealing temperature of $52^{\circ} \mathrm{C}$. The MSP results were subsequently electrophorized using $2.4 \%$ agarose gel with 100 Volt for 45 minutes and analyzed using ImageJ software to measure the band intensity.

\section{$R N A$ extraction and cDNA synthesis}

The RNA was extracted using QuickRNA Miniprep Plus Kit R1058 (Zymo Research, USA), and the cDNA was synthesized from isolated
RNA using Rever'Tra Ace ${ }^{\circledR}$ qPCR RT Master Mix with gDNA Remover (Toyobo, Japan).

\section{Analysis of $\mathrm{mRNA}$ expression of TRPA1}

The qRT-PCR THUNDERBIRDTM SYBR ${ }^{\circledR}$ qPCR Mix (Toyobo, Japan) was used to analyze the mRNA expression of TRPA1. The relative expression of the targeted gene was previously normalized using GAPDH as the calibrator. We used specific designed primers as follows: (F) 5'CGCAGCCTGAGGAAGATG-3' and (R) 5'TGAGTCCTTCCACGATACCA-3'. The final amplification product had $96 \mathrm{bp}$ in length with an annealing temperature of $60^{\circ} \mathrm{C}$. Furthermore, the relative expression of TRPA1 was analyzed using the Livak method.

\section{Statistical analysis}

The data distribution of DNA methylation and the mRNA expression level was abnormally distributed $(\mathrm{p}<0.05)$, therefore we used the MannWhitney test. In addition, Spearman's rank test was used to determine the correlation between DNA methylation level and mRNA expression of TRPA1 as well as its correlation with pain level. The statistical significance set at $\alpha<0.05$.

\section{RESULTS AND DISCUSSION}

\section{The characteristics of participant}

The participant's characteristics were covered age, family history of endometriosis, smoking activity, soya consumption, pain level, and pain symptoms during the menstrual cycle. The average age of women with endometriosis was $35.6 \pm 1.08$, while the average age of women without endometriosis was $32.6 \pm 0.9$ (Table 1).

In endometriosis women, it was found $15 \%$ had historical endometriosis, 10\% were active smokers, $35 \%$ were passive smokers, and $15 \%$ always consumed soya. Also tend to have pelvic pain, of which $80 \%$ of them had moderate-severe pain levels. $60 \%$ of women with endometriosis were reported to experience pain during menstruation (Table 1). In this study, we just described the characteristics of subjects in smoking and soy consumption habits, was not analyzed the relationship between the two with the incidence of endometriosis and pain in 
endometriosis. Current studies have stated a relationship between cigarette exposure smoke and the occurrence of endometriosis. Cigarette smoke can reduce the synthesis of estradiol (E2) levels and progesterone deficiency. (Bravi et al., 2014; Sanders et al., 2002). In addition, epigenetic alteration is the etiopathology of endometriosis (Guo, 2009). Soy polyphenols have been shown to inhibit DNA methyltransferases and histone deacetylases in cancer cell lines and restoring aberrant island CpG methylation (Qin et al., 2009). The similarities in the characteristics of cancer and endometriosis have been described in previous studies. (Koukoura et al., 2016)

Table 1. The characteristics of the participants.

\begin{tabular}{|c|c|c|}
\hline Variable & $\begin{array}{l}\text { Endometriosis } \\
n=20\end{array}$ & $\begin{array}{l}\text { Without } \\
\text { endometriosis } \\
\mathrm{n}=20\end{array}$ \\
\hline Age, mean \pm SD & $35,6 \pm 4,87$ & $32,6 \pm 4,17$ \\
\hline \multicolumn{3}{|c|}{ Family history of endometriosis, $\mathrm{n}(\%)$} \\
\hline Yes & $3(15)$ & $0(0)$ \\
\hline No & $17(85)$ & $20(0)$ \\
\hline \multicolumn{3}{|l|}{ Active smoker, n (\%) } \\
\hline Yes & $2(10)$ & $0(0)$ \\
\hline No & $18(90)$ & $20(100)$ \\
\hline \multicolumn{3}{|l|}{ Passive smoker, n (\%) } \\
\hline Yes & $7(35)$ & $3(15)$ \\
\hline No & $13(65)$ & $17(85)$ \\
\hline \multicolumn{3}{|c|}{ Soya consumption, $\mathrm{n}(\%)$} \\
\hline Severe -always & $3(15)$ & $5(20)$ \\
\hline Hardly never - seldom & $17(85)$ & $15(75)$ \\
\hline \multicolumn{3}{|l|}{ Pain level, n (\%) } \\
\hline Pain (score $4-5)$ & $16(80)$ & $0(0)$ \\
\hline No pain $($ score $0-3)$ & $4(20)$ & $20(100)$ \\
\hline \multicolumn{3}{|c|}{ Pain symptoms during the menstrual cycle, $\mathrm{n}(\%)$} \\
\hline Along the period & $12(60)$ & $0(0)$ \\
\hline Before and after periods & $4 \quad(20)$ & $0(0)$ \\
\hline Never & $4(20)$ & $0(0)$ \\
\hline
\end{tabular}

Women with endometriosis experienced more pain than women without endometriosis, especially during menstrual periods. Stratton and Berkley also proved that $70 \%$ of women with endometriosis who underwent laparoscopy had chronic pelvic pain, and only $5 \%$ had no symptoms (Stratton \& Berkley, 2011).

Women with endometriosis felt pelvic pain at the peak of premenstrual and subsided after menstruation. Chapron stated that endometriosis with below $5 \mathrm{~mm}$ invasion in the peritoneal surface is associated with dysmenorrhoea's severity (Chapron et al., 2003).

$\mathrm{SD}=$ Standard Deviation; $\mathrm{n}=$ number of sample.

\section{The mRNA expression of TRPA1 in endometriosis}

In endometriosis women, the mRNA expression level of TRPA1 increased in respectively 17.34 and 1.51 fold than endometrial without endometriosis. Furthermore, there was a significant difference in the mRNA expression between peritoneal and endometrial endometriosis samples $(\mathrm{p}<0.001)$ (Figure 1).
Giudice argued that the presence of adhesion and scars in the pelvis was thought to be caused by cytokines and prostaglandins produced by peritoneal endometriosis (Giudice, 2010). He was supported by Greaves et al. (2014) who believed that the mRNA expression of the $\mathrm{P} 2 \mathrm{X} 3$ receptor, sodium channel, voltage-gated, type XI, alpha (SCN11A), TRPV1, and TRPA1 increased 
significantly in the peritoneal of women with endometriosis (Greaves et al., 2014).

However, the result found that was no significant difference between the endometrial case group and the control group $(p>0.05)$ (Figure.1). A previous study suggested that the TRPA1 expressed in mice's and human's endometrial by primary sensory neuron as the main integration of nociceptors and found (Fernandes et al., 2012).

In this study, the mRNA expression level of TRPA1 in endometrial endometriosis was increased 1.5 fold than normal endometrial
(Figure 1). It is supported by the stated that the endometrial anomaly which occurs in women with endometriosis was identified in the structure, cell proliferation, immune components, adhesion molecules, enzymes and proteolytic inhibitors, and production, steroids, and cytokines responses, and genes and proteins expression (Sharpe-timms, 2001). In addition, the endometrial cells in women with endometriosis were functionally different from endometrial cells in women without endometriosis. (Banu et al., 2008).

\section{The Difference of mRNA expression level of TRPA1 gene between endometriosis and without endometriosis}

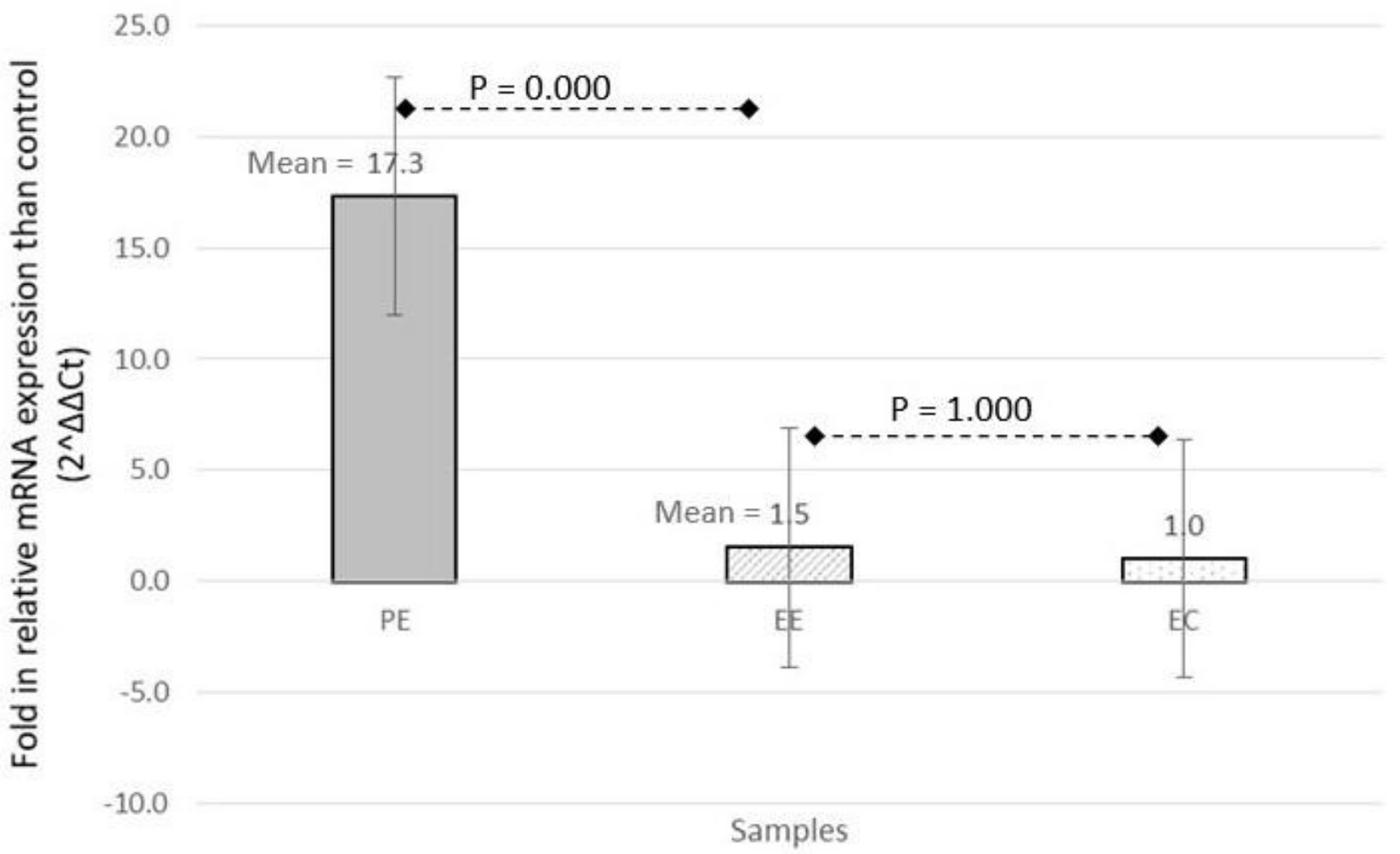

Figure 1. The differences between the mRNA expression level of TRPA1 in peritoneal endometriosis and endometrial samples of women with endometriosis as well as endometrial sample of women without endometriosis; $\mathrm{EE}=$ endometrial endometriosis samples; $\mathrm{PE}=$ peritoneal endometriosis samples; $\mathrm{EC}=$ endometrial samples without endometriosis (control); $\mathrm{N}$ (number of samples) $=20 ; \mathrm{P}=$ significant value; Mann-Whitney test. 


\section{The DNA methylation level of TRPA1 in endometriosis}

Analysis of DNA methylation level of TRPA1 was evaluated by measuring the band intensity of the MSP gel electrophoresis product using the Image J software (Figure 2). The DNA methylated level was calculated by dividing the methylatedband intensity with the methylated and unmethylated bands' total intensity, hence multiplying by 100\% (Ocktariyana et al., 2019).

This study found that the DNA methylation level of TRPA1 in peritoneal and endometrial endometriosis was unmethylated than endometrial without endometriosis. Nevertheless, there was no significant difference in the DNA methylation level of TRPA1 between both peritoneal and endometrial endometriosis, as well as endometrial without endometriosis (respectively, $\mathrm{p}>0.05$ ) (Figure 3).

In the last few years, studies about epigenetics aberration and biomolecular-based endometriosis proved epigenetics was the pathogenesis of endometriosis (Nasu et al., 2011). Epigenetics is the regulation of gene expression without making any changes in the DNA sequence. One of the examples of epigenetic modifications, which occurred in endometriosis, was DNA methylation. DNA methylation was the control mechanism for gene expression inherited and happened in certain tissues (Nasu et al., 2011).

Hypermethylation and hypomethylation in the promoter region rich in $\mathrm{CpG}$ islands developed impaired gene expression.
Hypomethylation is associated with increased mRNA gene expression, while hypermethylation is decreased mRNA expression (Portela \& Esteller, 2010).

\section{Correlation between DNA methylation level and $m R N A$ expressions of TRPA1 in endometriosis}

This study found no correlation between DNA methylation level and mRNA expression of TRPA1 in both peritoneal and endometrial endometriosis (respectively, $\mathrm{p}=0.990 ; \mathrm{p}=0.542$ ) (Table 2). However, (Buchheit et al., 2012) showed that, due to environmental factors, the epigenetic alteration induced inflammatory cytokine metabolism, steroid response, and opioid sensitivity, contributing to chronic pain regulation and disease development. Alvarado et al. (2015) also stated that DNA methylation regulated neural plasticity gene expression in the neuroanatomic, functional, morphological, physiological, and molecular levels, which showed throughout neuroaxis of persistent pain.

It's may other mechanisms that induced the alteration of TRPA1 expression in endometriosis. The gene expression regulation required various components, including protein regulation, such as specific transcription factors which interacted with certain promoter regions. (Xin et al., 2008). This study suspected that other epigenetic mechanisms such as miRNA and histone modification also played an important role in altering pain mechanisms.

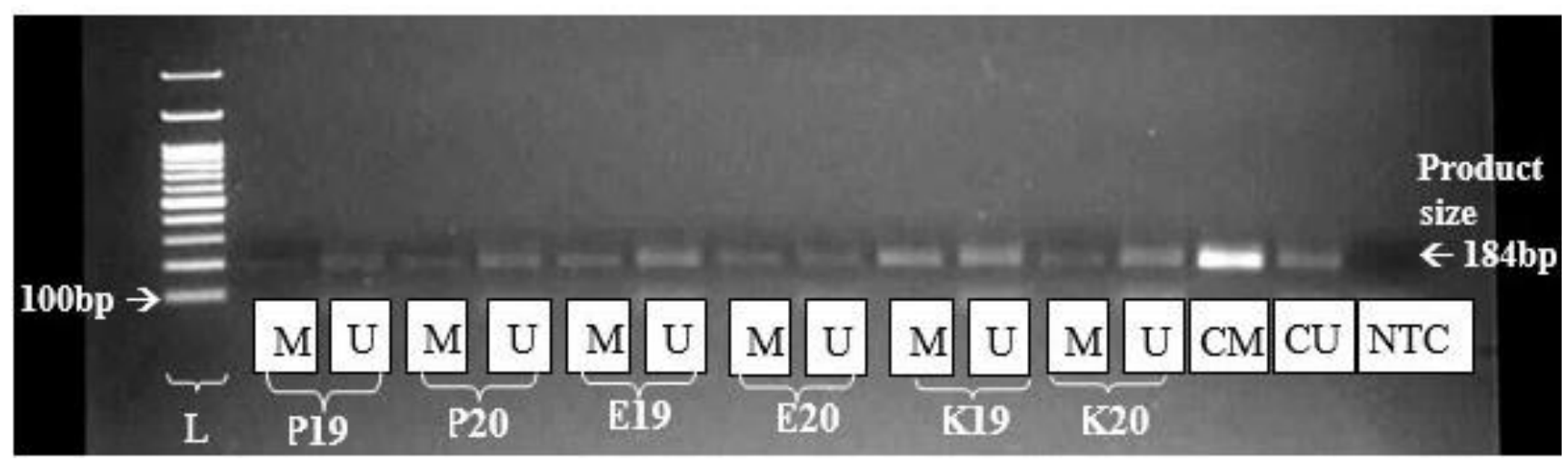

Figure 2. Visualization of the MS-PCR gel electrophoresis product of TRPA1 gene on 2.4\% agarose gel (Promega), product MS-PCR size was 184 bp (EpiTect MSP Kit (QIAGEN)), Hyperladder ${ }^{\mathrm{TM}} 100$ bp (Bioline) $\mathrm{L}=$ ladder; $\mathrm{E}=$ endometrial samples of women with endometriosis; $\mathrm{P}=$ peritoneal endometriosis samples of women with endometriosis; $\mathrm{K}=$ endometrial sample of women without endometriosis; $\mathrm{M}=$ Methylated; $\mathrm{U}=$ Unmethylated; $\mathrm{CM}=$ Methylated control (EpiTect Control DNA, methylated buman 100\% (QIAGEN); CU = Unmethylated control (EpiTect Control DNA, unmethylated buman 100\% (QIAGEN)); NTC $=$ Non template control. 


\section{The Difference of DNA Methylation level of promoter region TRPA1 gene between endometriosis and without endometriosis}

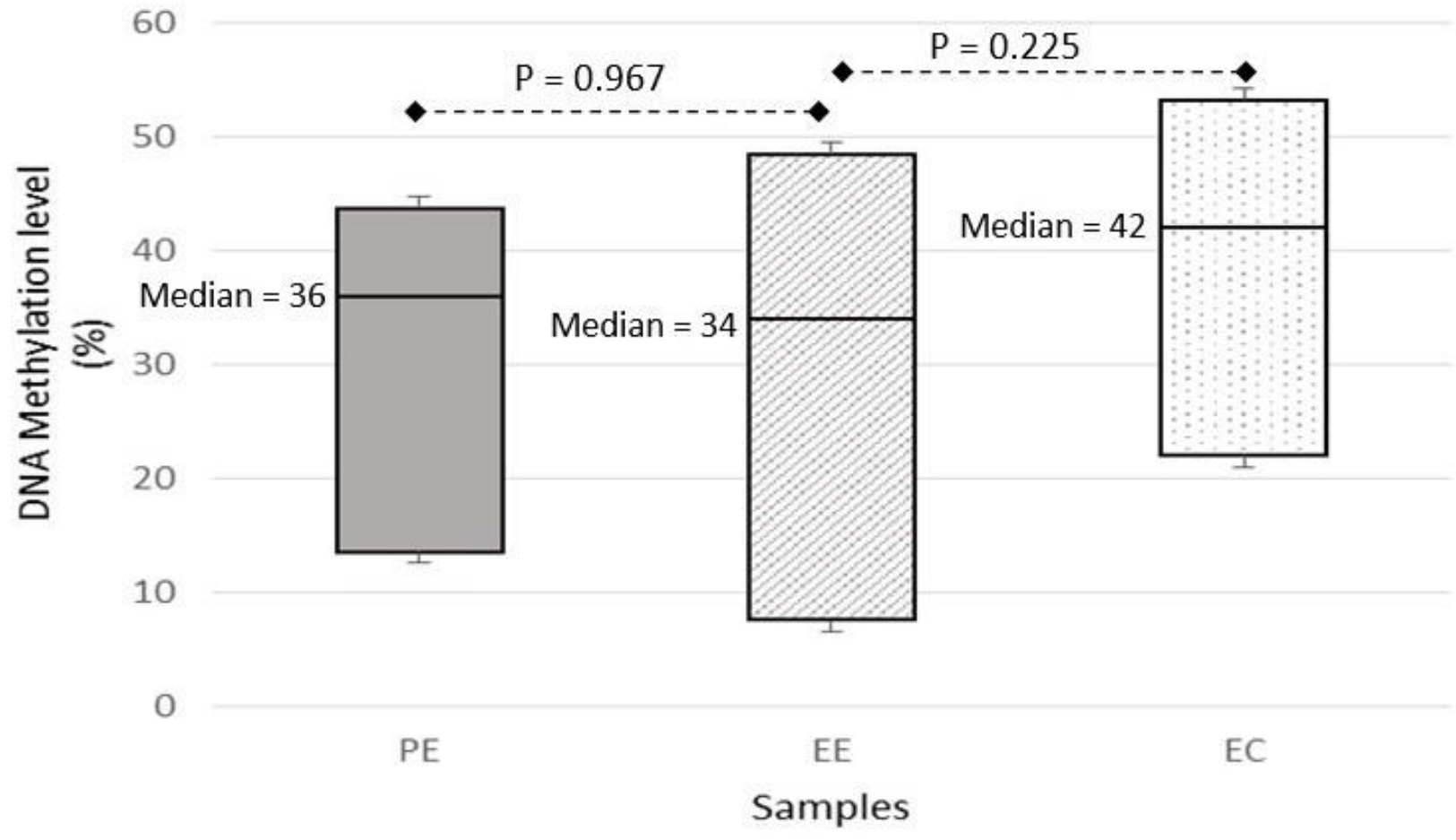

Figure 3. The difference of TRPA1's DNA methylation level in women with endometriosis compared to women without endometriosis; $\mathrm{EE}=$ endometrial samples of women with endometriosis; $\mathrm{PE}=$ peritoneal endometriosis samples of women with endometriosis; EC = endometrial samples of women without endometriosis; $\mathrm{P}=$ significant value; Mann Whitney test.

Table 2. Correlation between DNA methylation level and mRNA expression of TRPA1 associated with pain level in endometriosis.

\begin{tabular}{llll}
\hline $\begin{array}{l}\text { Correlation between DNA methylation level } \\
\text { and mRNA expression of TRPA1 }\end{array}$ & $\mathbf{n}$ & $\mathbf{r}$ & $\mathbf{p}$ \\
\hline $\mathrm{EE}$ & 20 & 0.003 & 0.990 \\
\hline PE & 20 & 0.145 & 0.542 \\
\hline
\end{tabular}

Correlation between mRNA expression of TRPA1 and pain level in endometriosis

\begin{tabular}{llll}
\hline EE & 20 & 0.341 & 0.141 \\
\hline PE & 20 & -0.093 & 0.698 \\
\hline
\end{tabular}

Correlation between DNA methylation level of TRPA1 and pain level in endometriosis

\begin{tabular}{llll}
\hline $\mathrm{EE}$ & 20 & -0.166 & 0.485 \\
\hline $\mathrm{PE}$ & 20 & -0.008 & 0.973 \\
\hline
\end{tabular}

$*$ Spearman rho test; $\mathrm{n}=$ number of sample; $\mathrm{r}=$ regression of correlation value; $\mathrm{p}=$ significant value; $\mathrm{EE}=$ endometrial sample of women with endometriosis; PE = peritoneal endometriosis of women with endometriosis. 


\section{Correlation between $m R \mathbf{N A}$ expressions of TRPA1 and pain in endometriosis}

This study showed no correlation between the mRNA expression of TRPA1 and pain level in both peritoneal lesion and endometrial tissue of women with endometriosis (respectively, $\mathrm{p}=$ 0.141; $p=0.698$ ) (Table 2). In line with Bautista et al., this study stated that TRPA1 is expressed when irritation occurs due to thermal and mechanical hypersensitivity, thereby increasing pain sensation. It is assumed that only a part of nociceptors is expressed by the receptors, even though there are many transmembrane receptors at the end of the unmyelinated type $\mathrm{C}$ nerve fibers in tissues (Bautista \& Julius, 2006).

This study proved that endometriosis did not experience thermal and mechanical stimuli which irritated both peritoneal and endometrial, but it's considered that prolonged inflammation could lead to increase receptor regulation for excitatory compounds such as TRPA1 (Julius et al., 2001; Harada, 2014; Fernandes et al., 2012). TRPA1 was indirectly modulated by pro-algesic agents, such as bradykinin, which acted via PLC-coupled receptors (Basbaum et al., 2010).

\section{Correlation between DNA methylation level of TRPA1 and pain in endometriosis}

This study showed no correlation between DNA methylation level of TRPA1 and pain level in peritoneal and endometrial endometriosis (respectively, $\mathrm{p}=0.458 \mathrm{p}=0.973)($ Table 2$)$.

The pain was characterized as endometriosis symptoms, yet its exact mechanism still could not be explained thoroughly. Besides, the pain symptom of women with endometriosis was atypical. There were women with endometriosis who experienced severe pain, which made them unable to do activities. In contrast, there were also women with endometriosis who did not experience pain. This difference was thought to be related to epigenetics, as it had been proven with the study on identical twins (Buchheit et al., 2012).

In contrast, Bel et al. (2014) performed a whole-blood DNA methylation analysis at 5.2 million different loci using MeDIP sequencing to identify which DMRs were associated with pain sensitivity and found that TRPA1 had the strongest DMRs in pain intensity. In addition, a study was suggested that there was a significant correlation between the high methylation level in the CpG island of TRPA1 and the numbers of neuropathic pain symptoms (Sukenaga et al., 2016). Based on these findings, there has not been any reported correlation between DNA methylation level of Nerve Growth Factor, TRPA1, and P2X purinoceptor 3 in endometriosis, although Muzii et al. (1996) suggested that the increase of COX-2 expression was associated with hypomethylation on the $\mathrm{CpG}$ islands of COX-2 in either eutopic endometrial or endometrial tissue of women with endometriosis. We assumed that DNA methylation was not the only factor behind the increased mRNA expression of TRPA1 in endometriosis.

The alteration of gene expression without affecting the DNA nucleotide base sequence was the concept of epigenetic. DNA methylation was not the only epigenetic mechanism, and there were several other mechanisms, namely histones modification and microRNA, which could also affect the mRNA expression of pain-coding genes. Therefore, further studies are needed to analyze other epigenetic mechanisms and enzymes that catalyzed the DNA methylation of the DNMT subtype in the pain-coding gene.

\section{CONCLUSION}

There was increased mRNA expression of TRPA1 in peritoneal endometriosis, perhaps revealed the pathogenesis of nociceptive-related pain. In addition, hypomethylation in peritoneal endometriosis and endometrial endometriosis women more hypomethylation than endometrial women without endometriosis. However, further study with a large number of samples to evidence of correlation epigenetic factors such as DNA Methylation in endometriosis-associated pain.

\section{ACKNOWLEDGEMENTS}

We gratefully thank the Ministry of Research, Technology, and Higher Education of Indonesia for the PDUPT 2019 grant. 


\section{REFERENCES}

Alvarado, S. et al. 2015. An epigenetic hypothesis for the genomic memory of pain. Frontiers in Cellular Neuroscience 9: 1-10.

Andersson, D. A., Gentry, C. Moss, S., \& Bevan, S. 2008. Transient receptor potential A1 is a sensory receptor for multiple products of oxidative stress. Journal of Neuroscience 28(10): 2485-94.

Bautista, D. M., Jordt, S. E., Nikai, T., Tsuruda, P. R., Read, A. J., Poblete, J., Yamoah, E. N., Basbaum, A. I., \& Julius, D. 2006. TRPA1 mediates the inflammatory actions of environmental irritants and proalgesic agents. Elsevier 124(6): 1269-82.

Banu, S. K., Lee, J. H., Starzinski-Powitz, A. \& Arosh, J. A. 2008. Gene expression profile and functional characterization of human immortalized endometriotic epithelial and stromal cells. Fertility and Sterility 14(2): 972-87.

Basbaum, A. I., Bautista, D. M., Scherrer, G., \& Julius, D. 2010. Cellular and molecular mechanisms of pain. NIH Public Access 139(2): 267-84.

Bell, J. T, Loomis, A. K., Butcher, L. M., Gao, F., Zhang, B., Hyde, C. L., Sun, J., Wu, H., Ward, K., Harris, J., \& Scollen, S. 2014. Differential methylation of the TRPA1 promoter in pain sensitivity. Nature Communications 5: 2978.

Bravi, F. Parazzini, F., Cipriani, S., Chiaffarino, F., Ricci, E., Chiantera, V., Viganò, P., \& La Vecchia, C. 2014. Tobacco smoking and risk of endometriosis : a systematic review and meta-analysis. BMJ Open 4(4:e006325): 1-9.

Buchheit, T., Van de Ven, T., \& Shaw, A. 2012. Epigenetics and the transition from acute to chronic pain. Pain Medicine.

Chapron, C., Fauconnier, A., Dubuisson, J. B., Barakat, H., Vieira, M., \& Bréart, G. 2003. Deep infiltrating endometriosis: Relation between severity of dysmenorrhoea and extent of disease. Human Reproduction 18(4): 760-66.

Clapham, D. E. 2007. SnapShot: Mammalian TRP channels. Cell 129: 220.

Das, P. M. \& Singal, R. 2017. DNA methylation and cancer. Journal of Clinical Oncology 22(22): 4632-4642.

Eisenberg, V. H., Weil, C., Chodick, G., \& Shalev, V. 2018. Epidemiology of endometriosis: A large population-based database study from a healthcare provider with 2 million members. BJOG: An International Journal of Obstetrics \& Gynaecology 125(1): 55-62.

Fernandes, E. S., Fernandes, M. A., \& Keeble, J. E. 2012. The functions of TRPA1 and TRPV1: Moving away from sensory nerves. British Journal of Pharmacology 166(2): 510-21.

Fernandes, E. S., Russell, F. A., Spina, D., McDougall, J. J., Graepel, R., Gentry, C., Staniland, A. A., Mountford, D. M., Keeble, J. E., Malcangio, M., \& Bevan, S. 2011. A distinct role for Transient Receptor Potential Ankyrin 1, in addition to Transient Receptor Potential Vanilloid 1, in tumor necrosis factor $\alpha$-induced inflammatory hyperalgesia and Freund's complete adjuvant-induced monarthritis. Arthritis Rheum 63: 819-29.

Francesca, F et al., 2007. Guidelines on pain management. European Association of Urology.

Giudice, L. C. 2010. Endometriosis. New England Journal of Medicine 362(25): 2389-98.

Greaves, E., Grieve, K., Horne, A. W., \& Saunders, P. T. K. 2014. Elevated peritoneal expression and estrogen regulation of nociceptive ion channels in." Journal of Clinical Endocrinology and Metabolism 99(9): 1738-43.

Guo, S. W. 2009. Epigenetics of endometriosis. Molecular Human Reproduction: 587-607.

Harada, T. 2014. Endometriosis: Pathogenesis and Treatment Endometriosis: Pathogenesis and Treatment. Springer Japan.

Hawker, G. A., Mian, S., Kendzerska, T., \& French, M. 2011.
Measures of adult pain: Visual analog scale for pain (VAS Pain), numeric rating scale for pain (NRS Pain), McGill pain questionnaire (MPQ), short-form McGill pain questionnaire (SF-MPQ), chronic pain grade scale (CPGS), short form-36 bodily pain scale (SF). Arthritis Care \& Research 63(S11): S240-52.

Hendarto, H. Prabowo, P., Moeloek, F. A., \& Soetjipto, S. 2010. Growth differentiation factor 9 concentration in the follicular fluid of infertile women with endometriosis. Fertility and Sterility 94(4): 758-760.

Howard, F. M. 1999. The role of laparoscopy in chronic pelvic pain: Promise and pitfalls. Obstetrics and Gynecological Survey 48(6): 357-87.

Julius, D. \& Basbaum, A. I. 2001. Molecular mechanisms of nociception. Nature 413: 203-210.

Koukoura, O., Sifakis, S., \& Spandidos, D. A. 2016. DNA methylation in endometriosis (review). Molecular Medicine Reports: 2939-2948.

Marinho, M. C., Magalhaes, T. F., Fernandes, L. F. C., Augusto, K. L., Brilhante, A. V., \& Bezerra, L. R. 2018. Quality of life in women with endometriosis: An integrative review. Journal of Women's Health 27(3): 399-408.

Muzii, L., Marana, R., Pedulla, S., Catalano, G. F., Caruana, P., Rizzi, M., Margutti, F., \& Mancuso, S. 1996. Endometriosis associated dysmenorrhea is not related to typical or atypical peritoneal implants. The Journal of American Association of Gynecologic Laparoscopist 3(4, supplement): S32-S.

Nasu, K., Kawano, Y., Tsukamoto, Y., Takano, M., Takai, N., Li, H., Furukawa, Y., Abe, W., Moriyama, M., \& Narahara, H. 2011. Aberrant DNA methylation status of endometriosis: Epigenetics as the pathogenesis, biomarker, and therapeutic target. Journal of Obstetrics and Gynaecology Research 37(7): 68395.

Ocktariyana, A., Hestiantoro, R., Rahmala, \& Asmarinah. 2019. DNA methylation of P2X3 receptor gene encoded pain marker protein in endometriosis. Journal of Physics: Conference Series 1246(1): 012031.

Pedersen, S. F., Owsianik, G., \& Nilius, B. 2005. TRP channels: An overview. Cell Calcium 38: 233-252.

Portela, A. \& Esteller, M. 2010. Epigenetic modifications and human disease. Nature Biotechnology 28(10): 1057-68.

Qin, W., Zhu, W., Shi, H., Hewett, J. E., Ruhlen, R. L., MacDonald, R. S., Rottinghaus, G. E., Chen, Y. C., \& Sauter, E. R. 2009. Soy isoflavones have an antiestrogenic effect and alter mammary promoter hypermethylation in healthy premenopausal women. Nutrition and Cancer 61(2): 238-244.

Sanders, S. R., Cuneo, S. P., \& Turzillo, A. M. 2002. Effects of nicotine and cotinine on bovine theca intema and granulosa cells. Reproductive Toxicology 16(6): 795-800.

Sharpe-Timms, K. L. 2001. Endometrial anomalies in women with endometriosis. Annals of the New York Academy of Sciences 943: 131-47.

Stratton, P. \& Berkley, K. J. 2011. Chronic pelvic pain and endometriosis: Translational evidence of the relationship and implications. Human Reproduction Update 17(3): 327-46.

Sukenaga, N., Ikeda-Miyagawa, Y., Tanada, D., Tunetoh, T., Nakano, S., Inui, T., Satoh, K., Okutani, H., Noguchi, K., \& Hirose, M. 2016. Correlation between DNA methylation of TRPA1 and chronic pain states in human whole blood cells. Pain Medicine 17(10): 1906-10.

Taylor, R. \& Lebovic, D. I. 2014. In: Stauss JF, Barbieri RL, Editors. Yen \& Jaffe's Reproductive Endocrinology. Seventh Ed. China: Elsevier Saunders (Seventh ed). pp. 56585.

Wu, Y. et al. 2015. Promoter Hypermethylation of Progesterone Receptor Isoform B ( PR-B ) ND ES SC RIB: 2294.

Xin, D., Hu, L., \& Kong, X. 2008. Alternative promoters influence 
alternative splicing at the genomic level. PLOS ONE 3(6).

Xue, Q., Lin, Z., Cheng, Y. H., Huang, C. C., Marsh, E., Yin, P., Milad, M. P., Confino, E., Reierstad, S., Innes, J., \& Bulun, S. E. 2007. Promoter methylation regulates estrogen receptor 2 in human endometrium perand endometriosis." Biology of Reproduction 77(4): 681-87.

Young, K., Fisher, J., \& Kirkman, M. 2015. Women's experiences of endometriosis: A systematic review and synthesis of qualitative research. Journal of Family Planning and Reproductive Health Care 41(3). 